Research, part of a Special Feature on Global Water Governance: Challenges and Future Scope

\title{
Policymakers' Reflections on Water Governance Issues
}

\author{
Joyeeta Gupta, Aziza Akhmouch, William Cosgrove, Zachary Hurwitz, Josefina Maestu and Olcay Ünver
}

ABSTRACT. The two cultures theory argues that policy makers and scientists have different cultures and difficulty in communicating with each other. Others argue that there is increasing co-production of knowledge. This essay aims to assess the concerns of policy makers based on our policy work, policy-related research work, and our day-to-day experiences in terms of three questions: What are the perceived major issues for water governance? What are the major challenges in the structure of the existing global water governance approach? What is the vision for improving global water governance? This essay combines views from governmental, hybrid, inter- and non-governmental policy makers. It argues that water covers so many issues, aspects, and sectors that a key challenge is whether water should be governed as a sector or as a cross-cutting issue. It looks at how this challenge plays out within the United Nations system and leads to specific goal setting, while missing an overall visionary approach and a legally binding system of governance; within the hybrid arena, where it leads to inclusive discussion but not necessarily triggering consensus decisions; within nation states, where it has led to a loss of focus and a multitude of gaps and overlaps; and within transnational cooperative projects, where it has led to multiple interpretations of what is good practice. It then identifies a series of research questions.

Key Words: coordination mechanism; drivers; global governance; global water governance; outside water box; world water scenarios

\section{INTRODUCTION}

Academics often take an abstract approach to analyzing governance. They have their own academic logic, theories, and methodological routes and are often disconnected from the real-life problems faced by policy makers from government, hybrid bodies, and inter- and non-governmental organizations (IGOs and NGOs, respectively). Both are evaluated differently by their peers. The gaps and the links have been studied in theories such as the two cultures theory, science-policy interface, and boundary work studies.

This paper does not take a theoretical perspective, but focuses on how different policy makers view the global water governance challenge. It addresses three questions: What are the perceived major issues for water governance? What are the major challenges in the structure of the existing global water governance approach? and What are the possible visions for improving global water governance? It is based on integrating the perspectives of the experienced policy makers on the above three questions.

This essay first presents a brief history of global water governance. It then reflects on the nature of the water problem, the nature of United Nations (UN) governance and hybrid water governance, and the way states are organizing their water governance. It then turns to project specific experiences of transnational cooperation. Each of these reflections has led to the identification of specific research questions.

\section{THE EVOLUTION OF GLOBAL WATER GOVERNANCE}

Global water governance can be divided into five fragmented arenas (water law, water policy, hybrid (public-private) policy making, the framing of water as an economic good, and the human rights arena). First, the water law arena includes hundreds of transboundary river agreements that have been negotiated over the last 500 years and the codification of water law by the International Law Association in the Helsinki Rules of 1966 and the Berlin Rules of 2004, and the United Nations Convention on the Law of the Non-Navigable Uses of International Watercourses of 1997, which is not yet in force. It includes regional agreements, such as the UN Economic Commission for Europe (UNECE) 1992 Convention for the Protection and Use of Transboundary Watercourses and International Lakes, its 1999 Protocol, and the European Water Framework Directive of 2000 (Dellapenna and Gupta 2008, 2009).

Second, the water policy arena is characterized by changing paradigms, from the hydraulic paradigm through the integrated water resource management (IWRM) paradigm to the notion that there are no easy panaceas. As water is not the exclusive mandate of any UN agency, there have been a series of UN-sponsored conferences, from the UN Conference on the Human Environment of 1972, the Mar del Plata Conference of 1977, the Water and Sanitation Decade of the 1980s, the UN Conference on Environment and Development of 1992, the Dublin Conference on Water of 1992, and the inclusion of water targets in the Millennium Development Goals (MDGs) of 2000. The diffuse nature of water governance in the UN, and the ad hoc commissions, such as the World Commission on Dams, led to the establishment of UN-Water in 2003 as a coordinating mechanism to promote coherence in the water field. Water policy has been also part of the development cooperation sector-the development banks and the various aid agencies-which has fed back into 
policy processes, such as those on the MDGs and those of the UN Commission for Sustainable Development. For example, the International Waters Programme of the Global Environment Facility has been focusing on developing country needs and providing resources to them.

Third, there is a hybrid policy arena (where state and non-state actors collaborate) with the establishment of the World Water Council and the Global Water Partnership (GWP). The annual World Water Week and the World Water Forums, which occur once every 3 years, provide a forum for experts, policy makers, and stakeholders to coalesce and discuss water issues. This leads to global learning and discursive processes (Pahl Wostl et al. 2008).

Fourth, the move toward defining water as an economic good has implied that global trade and investment regimes- the GATT and World Trade Organization (WTO), the International Convention on the Settlement of Investment Disputes, and the 3000 or so bilateral investment treatiesalso govern water. With the failure of some public-private water contracts, regulatory impacts are being generated through confidential arbitration proceedings, which only rarely leak out to the public, such as the arbitration on the Cochabamba case. The resolve to collectively deal with the global economic crisis, to reform the flawed institutions and regulations, and to bring transparency to the international system seems to have lost its momentum after 2 years. Weaknesses in the WTO frameworks and examples of protectionism curtail effective global governance. Both the crisis and how the multilateral financial institutions (MFIs) deal with it have implications for water governance.

Finally, in the human rights arena, in 2008, the UN Human Rights Council launched a 3-year process to analyze the human right to water, and in 2010, the UN General Assembly adopted the Human Right to Water and Sanitation with 122 votes (Gupta et al. 2010) and the UN Human Rights Council also adopted a Resolution on the subject.

The governance record shows that the water field has no natural center of gravity at the global level; that there is a variety of competing actors and interests; and there is no real consensus process to deal with water science, although there are a few specialized conferences in the field.

\section{GOVERNING A CROSS-CUTTER: CURSE OR OPPORTUNITY?}

We now turn to the nature of water. Water is a wicked problem (because of its inherent complexity and the variation in the distribution of costs and benefits of water governance in society) and a moderately unstructured problem (because there is a lack of consensus on the nature of the problem and on the values that need to be used to deal with water). Some degree of consensus exists in the MDGs and some other documents, but these take only a partial perspective. Can creative thinking and experience help us "structure" the water problem?
Water's cross-cutting nature calls for those working in the water field ("water box") to understand the externalities of the state, as well as use and management aspects of water. They must inform those outside their field so that they can explicitly incorporate water into their decision-making processes. This is because the drivers of water use and abuse are mostly external forces, over which water managers have little, if any, control, whereas the environment within which they operate is influenced by decisions that are made in other public, private, and civil sectors. This complex governance landscape is described below. The World Water Development Report (World Water Assessment Programme (WWAP) 2009) states that human activities and processes can exert pressures on water resources. These human activities are, in turn, affected by technological innovation, institutional and financial conditions, and climate change. Improving living standards and changing consumption patterns threaten the sustainability of water resources and environmental services. The WWAP (2012; Cosgrove and Cosgrove 2012) examines ten drivers (agriculture; climate change and variability; demography; economy; security; ethics; society and culture (including questions of equity); governance and institutions (including the right to water); infrastructure; politics; and technology, examined along with water resources and ecosystems) in relation to their internal dynamics, trends, and how they interact with water resources. Many of these drivers are closely linked to each other and often reinforce each other. The causal links among these drivers show the interconnectedness of the governance spheres and help leaders to identify the opportunities for macro coherence, investment efficiency toward multiple objectives, and minimizing adverse and unwanted consequences of their policies.

Water is connected to and impacted by issues such as climate change, energy security, food shortages and prices, the economic crisis, and troubled financial markets. How these are addressed and if the water component in each is explicitly incorporated will determine the future of water and set/relax the constraints for water governance.

It is easier to explain the links between water and energy, agriculture, development, security and others and, more recently, between water-energy-food-climate change and its subsets to those outside the water field, than to use the integrated water resource management (IWRM) concept. The former approach may be a more diplomatic way to explain to others that they need to take water issues into account in their planning process. There are examples of how water is either assumed to be available without constraint (Commission on Growth and Development 2010) or only implied (Food and Agriculture Organization (FAO) 2008) or scarcely referred to, as in the MDGs, except in reference to drinking water and sanitation. The (mis)perception of water as a sector has led to water being ignored in the climate change documentation in 2008. Official development assistance accounting procedures 
track allotments to drinking water and sanitation, whereas other uses of water tend to be lumped with other items in the energy, agriculture, or other sectors.

For example, rain-fed agriculture is often governed by a complex of land use, energy/biofuel, and climate change policies; irrigation by global food, environmental, technology, and financial governance; and productivity issues and fertilizer use by energy and environmental governance, subsidies, food security, and trade policies. Global water governance may thus have to deal with a variety of issues, including those emanating from genetic modification, waterefficient plant strains, in vitro meat production, land grabs for energy (e.g., Africa), and the like.

How can the unstructured problem of water be structured? Should water be dealt with as a sector? Or should water be linked with all other sectors? If the former, how can water governance "outside the box" be promoted and implemented? If the latter, how can the protection of water-specific interests be championed?

\section{THE UNITED NATIONS: CHALLENGES AND OPPORTUNITIES}

\section{Strong in Setting Priority Goals, Weak in Governance Frameworks}

We now turn to whether the UN is able to govern water. The $\mathrm{UN}$ is successful in setting goals and guidelines for the global community. Internationally agreed objectives, such as the MDGs, have guided the actions of governments, the UN bodies, and the international community. The UN General Assembly Resolution of July 2010, recognizing water as a human right, has reinforced the importance of ensuring access to water and sanitation, especially for the very poor. Both these instruments have helped to create a voice for marginalized people, and whereas one tries to channel resources for them, the other tries to empower them by giving them rights.

However, beyond the issue of meeting the needs of the most vulnerable, the UN-Water governance arena lacks a clear focus and loci for action by the water community at global scale. Some member states and international organizations claim that the current system is falling short of what is needed for effective water governance. The 1997 Watercourses Convention is not and may never enter into force. The 1992 ECE Convention for the Protection and Use of Transboundary Watercourses and International Lakes, which created a framework for IWRM and cooperation for transboundary rivers in the UNECE region, is in force. However, the contrast between European and global regulatory systems demonstrates that we live in a multi-speed world. Water conventions have not yet provided a legitimate forum for reconciling diverse interests and integrating all relevant aspects through the negotiation of legally binding decisions, comparable to the 1992 Rio Conventions on Climate Change and Biodiversity.

The process beyond the global summit of 2012 (Rio+20) offers an opportunity to table proposals on targets and approaches for water governance beyond 2015, and to increase the priority to be given to water management in the national and international agenda, thus raising its political profile. This can be undertaken by demonstrating the contribution of water governance to poverty reduction and economic development, and signaling those actions that can contribute to sustainability. Hence, the WWAP has been arguing that the water community needs to not only talk to each other (the convinced) but also reach out to other major global processes and actors.

The implications for research are: How can the role of the UN as goal setter be strengthened; and how can the legitimate and legally binding instrument of global treaties be used more effectively for comprehensive regulation in the water arena?

\section{United Nations-Water: Coordination "Light"}

As most UN agencies have activities that directly or indirectly deal with water, the international water community has been seeking coherence and coordination of UN-wide water-related activities. In 2003, UN-Water was set up as a light coordinating mechanism to replace the Administrative Committee on Coordination (ACC) Sub-Committee on Water Resources. With 30 members, which are UN agencies and some two dozen professional organizations and NGOs as partners, UN-Water's mandate and resources are limited. It has a deliberately light structure, with two staff members who support coordination and a number of task forces. UN-Water has been influential in coordinating the $\mathrm{UN}$ in specific themes, especially given its limited resources. It is also increasingly acquiring some authority, as the UN General Assembly has formally asked UN-Water to carry out specific tasks. However, meeting the task of effective steering of UN agencies may require a body that has significantly more power and resources than UNWater currently has. On the other hand, UN-Water's light coordination status may provide it more room for diplomatic maneuvering within the $\mathrm{UN}$ agencies. The recent new strategic directions of UN-Water, the increasing number of global partners, and the policy briefs being issued on key issues show some indications of UN-Water activities and the type of role it can play. There are efforts to widen its activities, and some member states and partners are willing to incrementally invest in these kinds of global water governance efforts.

The success of global water governance also depends on improved interface with the wider audiences. There needs to be a clear program to interact with the media, water operators, local authorities, and key NGOs to help make water 
governance more transparent, more accessible, and more responsive to public concerns. This has triple dividends because it creates partnerships, provides legitimacy to social instruments in water management, and improves capacity and ownership. The global community needs to exploit the new communicative tools and social networks for public discussion and debate.

This implies more research: Is a light coordination mechanism an effective tool for governing water through its strong diplomatic and yet modest character in bringing large and small UN agencies together and in interfacing with the broader public? Or do the triple dividends of interfacing with the larger public, as well as coordinating water in the UN, call for a much stronger coordination mechanism?

\section{HYBRID BODIES: STRONG ON PROMOTING AWARENESS; WEAK ON DECISION MAKING}

The call to engage non-state actors has been met, to a large extent, by hybrid bodies. Successful governance systems call for both bottom-up input and top-down initiatives (Fowler et al. 2010). The World Water Council is an international organization with such characteristics. Established in 1996 by water specialists and organizations, its Board of Governors is composed of members from intergovernmental institutions; governments and government authorities; enterprises and facilities; civil society organizations and water user associations; and professional associations and academic institutions.

The Council aims "to promote awareness, build political commitment and trigger action on critical water issues at all levels, including the highest decision-making level, to facilitate the efficient conservation, protection, development, planning, management and use of water in all its dimensions on an environmentally sustainable basis for the benefit of all life on earth" (WWAP 2009).

By providing a platform to encourage debates and exchanges of experience, the Council aims to reach a common strategic vision on water resources and water services management, and the Council's initiatives and activities feed its flagship activity, the World Water Forum (WWF). The first WWF in Marrakesh, Morocco, in 1997, recommended action to recognize the basic human need for access to clean water and sanitation and called for effective mechanisms for the management of shared waters, to support and preserve ecosystems, to encourage the efficient use of water, to address gender equity issues in water use, and to encourage partnership between the members of civil society and governments. The Council created a strategic vision through a participative process, leading to the World Water Vision (Cosgrove and Rijsberman 2000) with its message that the world water crisis is a governance crisis. The Vision emphasized the need for people at the local level to work closely with governments and NGOs to meet everybody's basic needs without degrading the environment.

The Vision was presented to the Second WWF in The Hague, The Netherlands, in March 2000. Although many questioned the Council's legitimacy to convene such meetings, the 5700 participants, the Ministerial Conference (which included 120 Ministers), and the Declaration of The Hague on Water Security in the 21st Century (Second World Water Forum 2000) show the significance of the meeting. Subsequent forums attracted greater numbers of participants. Over 20,000 people attended the Fifth WWF in Istanbul, Turkey in 2009, and similar numbers are expected in future forums.

The GWP, founded in 1996, focused on developing the conceptual framework of IWRM based on the Dublin Principles (International Conference on Water and the Environment 1992) and establishing regional Technical Advisory Committees as start engines for raising awareness on IWRM in the regions. It defined IWRM as "the coordinated development and management of water, land, and related resources in order to maximize economic and social welfare without compromising the sustainability of vital environmental systems." The GWP is linked to the country level and focuses on action. In conjunction with the World Water Council, the GWP network held national and regional dialogs that led to its seven regional "Vision to Action" documents at the Second WWF, together with the overall Framework for Action (GWP 2000). This established the GWP as a key body on IWRM at the global and regional levels. Together with the UN Environment Programme (UNEP) and the UN Development Programme (UNDP), GWP is undertaking a global assessment of IWRM, which was launched in 2012 at Rio+20. The World Water Council and the GWP are partners of UN-Water. These bodies are strong on promoting awareness, and this is a necessary condition for promoting water governance. However, as they are not so good at taking binding decisions, some other organization needs to do so.

This story line has implications for research: How can nonUN governance efforts and UN governance efforts be synchronized and/or improved? How can the awareness building and policy triggering function of the World Water Council lead to legitimate and legally binding decisions within a UN framework? How can the specific characteristics of UN and non-UN agencies be optimized in a cooperative framework?

\section{MULTI-LEVEL GOVERNANCE ARRANGEMENTS: MULTIPLE ARRANGEMENTS, BUT FRAGMENTED}

Clearly, water is not just a global but a multi-level governance challenge. Reforming water policy requires an understanding of existing complex institutional settings. The Organisation for Economic Co-operation and Development (OECD) has 
Table 1. Key multilevel governance challenges in OECD countries' water policy making. Source: OECD Water Governance Survey (2010)

\begin{tabular}{|c|c|}
\hline Description of the "gap" & Examples of countries or regions \\
\hline $\begin{array}{l}\text { Funding Gap : Unstable or insufficient revenues undermining } \\
\text { effective implementation of water responsibilities at sub-national } \\
\text { level or for crossing policies }\end{array}$ & $\begin{array}{l}\text { Australia, Belgium (Flanders), Chile, France, Greece, Israel, Korea, } \\
\text { Mexico, New Zealand, Portugal, Spain, United States (Colorado) }\end{array}$ \\
\hline $\begin{array}{l}\text { Capacity Gap: Insufficient scientific, technical, infrastructural } \\
\text { capacity of local actors to design and implement water policies } \\
\text { (size and quality of infrastructure) }\end{array}$ & $\begin{array}{l}\text { Australia, Belgium (Flanders), Chile, Greece, Italy, Korea, } \\
\text { Netherlands, Portugal, Spain, United Kingdom, United States } \\
\text { (Colorado) }\end{array}$ \\
\hline $\begin{array}{l}\text { Policy Gap : Sectoral fragmentation of water-related tasks across } \\
\text { ministries and agencies }\end{array}$ & $\begin{array}{l}\text { Belgium (Flanders), Canada, France (subnational actor), Greece, } \\
\text { Israel, Italy, Korea, Spain (subnational actor), United States } \\
\text { (Colorado) }\end{array}$ \\
\hline $\begin{array}{l}\text { Administrative Gap : Geographical "Mismatch" between } \\
\text { hydrological and administrative boundaries }\end{array}$ & $\begin{array}{l}\text { Australia, Greece, Italy, Korea, Netherlands, Portugal, Spain, United } \\
\text { Kingdom, United States (Colorado) }\end{array}$ \\
\hline $\begin{array}{l}\text { Information Gap: Asymmetries of information (quantity, quality, } \\
\text { type) between different stakeholders involved in water policy, } \\
\text { either voluntary or not }\end{array}$ & $\begin{array}{l}\text { Australia, Chile, Italy, Korea, Netherlands, New Zealand (subnational } \\
\text { actor), United Kingdom, United States (Colorado) }\end{array}$ \\
\hline $\begin{array}{l}\text { Accountability Gap : Difficulty to ensure the transparency of } \\
\text { practices across the different constituencies }\end{array}$ & $\begin{array}{l}\text { Belgium (Flanders), Chile, Greece, Italy, Korea, Mexico, } \\
\text { Netherlands, Portugal, United States (Colorado) }\end{array}$ \\
\hline $\begin{array}{l}\text { Objective Gap: Different rationalities creating obstacles for } \\
\text { adopting convergent targets }\end{array}$ & Belgium (Flanders), Israel, Korea, Portugal \\
\hline
\end{tabular}

systematically collected water governance data from 17 OECD member countries (OECD 2011). This survey led to the following insights.

No systematic correlation can be drawn between a given country's institutional organization (unitary vs. federal) and the institutional mapping of water policy, which also relies on environmental, spatial, and hydrological considerations. A pervasive feature of water governance systems is the lack of a "master plan" for assigning water-related tasks across ministries and levels of government. Several ministries, public agencies, and departments are usually involved in water policy because of the interconnectedness of different issues (agriculture, energy, etc.), thus generating fragmented policy and the inherent risks of "silo" approaches in the absence of inter-ministerial coordination.

In addition, local actors (e.g., municipalities, river basin authorities) and supranational entities (e.g., the European Union) are involved in water policy, which requires efficient tools to manage the mutual dependence across levels of government and fosters a spatial approach (rural, urban, crossborder) in water policy design and implementation. An OECD "Multilevel Governance Framework" has identified seven categories of commonly experienced coordination "gaps" irrespective of the specific institutional setting that operates in a country (see Table 1 ).

Understanding multi-level water governance challenges requires a holistic approach. For instance, a country with fragmented water policy (policy gap) may also suffer from contradictory targets between public actors (objective gap), which may not facilitate information sharing (information gap) and is likely to undermine capacity building at a subnational level (capacity gap) as local actors, users, and private actors would have to multiply efforts to identify the right interlocutor in the central administration. This implies recognizing the impediments to effective coordination of public actors at administrative, funding, knowledge, infrastructural, and policy levels in order to address water "gaps."

Options for enhancing policy coordination include a framework for combining tools, funds, and organizations or establishing a multi-stakeholder platform for dialog for integrated water policy at all levels. This does not imply the creation of a single "water ministry" in the OECD region. Inter-ministerial bodies, high-level structures, and line ministries are the main governance tools used in upper horizontal coordination of water policy. More than half of the OECD countries surveyed have created these kinds of platforms for dialog and action between public actors in charge of water policy at the central government level. Other initiatives include contracts between levels of government, performance indicators, regulations, coordinating agencies, river basin organizations, water information systems, and financial transfers across levels of government. Intermunicipal collaboration, which is often used by subnational governments as a means to reach a "critical mass," increases efficiency, enhances capacity in water policy, and fosters lower horizontal coordination.

The OECD has designed generic "preliminary guidelines on public governance for integrated water policy." There is no 
one-size-fits-all model for enhancing public governance in the water sector and overcoming implementation of institutional obstacles. One governance tool can help bridge several gaps, and a single gap may require the adoption of multiple tools. In the absence of an optimum, the response to water governance challenges relies on place-based approaches taking into account spatial specificities and local concerns. However, a common vision of all levels of government, as developed by the 2030 Water Agenda recently adopted by Mexico, is still required to overcome fragmentation, design shared objectives including civil society, craft governance structures, and create institutional incentives to think out of the "water box."

Specific research questions that emerge from this discussion are: What is the relationship between a governance framework at global level and that at national through to local level? Are gaps inevitable in wicked, unstructured problems, or are there ways to overcome these gaps? How realistic and implementable is a comprehensive approach to water governance that can take all sectors, actors, perspectives, and impacts on the environment into account? If this is not realistic, what is the second best alternative? Can fragmentation in policy be overcome through mainstreaming water in other policy sectors? How can such mainstreaming be achieved?

\section{THE ROLE OF POWERFUL ACTORS IN WATER GOVERNANCE: FINANCIAL INSTITUTIONS AND SOVEREIGN GOVERNMENTS}

Critical actors in water governance include both lenders (e.g., multilateral financial institutions (MFI)) and borrowers of development finance whose loans impact on water governance. Hence, lenders should provide incentives for strengthening governance, include safeguards for protecting people dependent on water services, and emphasize best practices in protecting water systems. However, many borrower governments have achieved substantial financial maturity, and have the ability to finance their own loans using national, rather than multilateral, accounts. This reduces the leverage of MFIs to shape development; at the same time, these MFIs are beginning to scale back loan conditionalities, as these would represent additional costs to borrower governments that are less likely to borrow anyway, due to their greater financial capacity. At the same time, without the crosscutting stakeholder input and safeguards that come with loans from MFIs, governments that have increasing financial sovereignty may contribute to negative water impacts. Increasingly, MFIs have tools and instruments to deal with water, but there are practical challenges that affect the implementation and success of these instruments.

For example, International Rivers (IR) has been monitoring a development policy loan from the World Bank to the Brazilian National Development Bank (BNDES) for the period 20082010 that aimed to improve BNDES' regulatory framework, including the creation of safeguards for hydropower finance.
However, BNDES allegedly did not implement all measures, and its activities have not been transparent to Brazilian civil society. The World Bank, which communicates with civil society and offers a venue to hear grievances, saw its attempt to guide BNDES in the creation of these new safeguards rebuked. This financial self-sufficiency of some countries has thus made it more difficult to study how development investments affect water systems at a domestic level.

One way to manage diverse interests is through participatory river basin planning. However, as water users increasingly interact and compete, some actors have greater influence than others. In Brazil, river basin actors may form a river basin committee to promote a specific use, including preservation. However, government planners such as Eletrobras and the Ministry of Mines and Energy that opt for hydropower development and intensive water uses for development have greater financial means than other actors to see their promoted uses become reality. Here, the global context can balance the politics of the national context-it can help to support the smallholders whose rights may be affected by intensive water uses. There is a dilemma here: to what extent can global water governance mechanisms effectively improve national governance; and to what extent should the choices of national actors in water governance systems be respected, although safeguards to protect civil society and smallholders become weaker?

International Rivers is also lobbying the World Bank over its new energy strategy and its return to large dams in Africa and Asia. The point is not a simple ideological opposition to large dams; rather, it becomes necessary to ask whether large dams actually meet the social goals of universal energy access for the poorest through research. Although the World Commission on Dams' (WCD) recommendations on large dams have been influential, their implementation has been limited.

Experiences with private-sector participation in water services lead to doubts about whether water privatization poses a longterm risk to societies and ecosystems. Water privatization may work in some contexts but not in others. The privatization model used in China (corporatization-privatization within the context of state-owned enterprises) could potentially combine efficiency and equity considerations, but may also compromise the situations of the urban and rural poor, smallholders, riverine families, and indigenous peoples.

Non-governmental organizations such as International Rivers, perceive that the global agenda is unresolved; lacking a larger governance framework with visions and tools about how river basins and different water systems should be managed that speaks to the changing political and economic terrains of water governance and power. Neither the existing $\mathrm{UN}$ agencies nor the hybrid bodies are seen as filling this governance gap, although they clearly play significant roles. 
This calls for further research: Which scientific paradigms and options are likely to work in specific contexts and why? To what extent and under what conditions can carefully crafted transnational influence be used to change and modify existing policies or projects in countries? Why are global water actors that have considerable influence still so invisible in terms of influence when it comes to specific projects? What are the potential and limits of conditionalities?

\section{CONCLUSIONS}

This paper set out to integrate the perspectives of policy makers in the water field in order to identify research questions that emerge from their perspectives. It points out that there is a vacuum in substantive global water governance; an absence of strong and legitimate institutions to promote water governance; that UN-Water attempts coordination, but its mandate and resources are limited; and that the hybrid agencies are trying to mobilize discussions on water issues, but there remain difficulties in channeling all this energy into decisionmaking processes. At the global through to local levels, societies are grappling with the difficulties in dealing with global water governance and its implications-should it be dealt with as a distinct sector or should water governance be integrated into other sectors. The IWRM framework places water at the center of the universe and is seen as less attractive as a concept by other ministries/actors and players. For them, perhaps, the notion of links with other sectors ("nexus") is less threatening and is easier to deal with.

Some argue in favor of a centralized water body, some for integrating water into other bodies, and yet others for a coordinating mechanism/law that governs water. The choices among these three options need further research.

What are possible visions for improving global water governance? Forecasts regarding water use and abuse and the impacts of climate change on water call for a manifold improvement in the way we govern our resources. This begs the questions: Can incremental approaches, including small changes at the margin of the UN system, deliver the results we are looking for? Does structural change imply a major rehaul of the UN system to take the water issue into account? Or does structural change imply parking the UN system and developing an alternative system of governance? Some argue that the UN is the only legitimate forum for setting global norms, creating a sense of community and leading to legally binding decisions. The questions are: Is this good enough? Do we have a viable alternative?

Responses to this article can be read online at: http://www.ecologyandsociety.org/issues/responses. php/5086

\section{Acknowledgments:}

Although all authors have contributed to this piece in their personal capacity, it may be appropriate to note that Josefina Maestu heads the United Nations - Water Decade Program on Advocacy and Communication; William Cosgrove is head of Ecoconsult Inc. Montreal (formerly president of the World Water Council); Aziza Akhmouch works at the Water Governance Programme of the Organisation for Economic Co-operation and Development; Olcay Ünver heads the World Water Assessment Programme; Zachary Hurwitz is the Policy Programme Coordinator of the International Rivers Network, and Joyeeta Guptawas a professor at the VU University Amsterdam until 31 December 2012, after which she was appointed as a professor at the University of Amsterdam; she is also a professor at the UNESCO-IHE Institute for Water Education, Delft, The Netherlands. This paper has been written as part of a Global Water System Project (GWSP) effort on global water water governance. Disclaimer: the views expressed in this article are those of the authors and are not necessarily those of the United Nations

\section{LITERATURE CITED}

Commission on Growth and Development. 2010. Post-crisis growth in developing countries: a special report of the Commission on Growth and Development on the implications of the 2008 financial crisis. World Bank, Washington, D.C., USA.

Cosgrove, C. E., and W. J. Cosgrove. 2012. The dynamics of global water futures driving forces 2011-2050. UNESCO, World Water Assessment Programme, Paris, France. [online] URL: http://www.unesco.org/new/fileadmin/MULTIMEDIA/ HQ/SC/pdf/The\%20Dynamics\%20of\%20Global\%20Water\% 20Futures.pdf

Cosgrove, J. W., and F. R. Rijsberman. 2000. World water vision: making water everybody's business. World Water Council, Marseille, France and Earthscan, London, UK.

Dellapenna, J., and J. Gupta. 2008. Toward global law on water. Global Governance 14(4):437-453.

Dellapenna. J., and J. Gupta, editors. 2009. The evolution of the law and politics of water. Springer Verlag, Dordrecht, The Netherlands. http://dx.doi.org/10.1080/02508060.2011.588785

Food and Agriculture Organization (FAO). 2008. Climate change, water and food security. Expert consultation held on 26-28 February 2008. HLC/08/BAK/2, FAO, Rome, Italy.

Fowler, R., A. Johnstone-Burt, N. Pennell, and I. Watt. 2010. Bottom up and country led: a new framework for climate 
change action. Booz and Company, New York, New York, USA.

Global Water Partnership (GWP). 2000. Towards water security: a framework for action. GWP Global Secretariat, Stockholm, Sweden.

Global Water Partnership. 2010. Water evaporates from the climate change negotiating text. GWP Global Secretariat, Stockholm, Sweden. [online] URL http://www.gwp.org/en/ Press-Room/Press-Releases/Water-evaporates-from-the-climatechange-negotiating-text/

Gupta, J., R. Ahlers, and L. Ahmed. 2010. The human right to water: moving toward consensus in a fragmented world. Review of European Community and International Environmental Law 19(3):294-305. http://dx.doi.org/10.1111/ j.1467-9388.2010.00688.x

International Conference on Water and the Environment (ICWE). 1992. The Dublin statement on water and sustainable development. Report of the International Conference on Water and the Environment, World Meteorological Organization, Dublin, Ireland. [online] URL: http://www.wmo.int/pages/ prog/hwrp/documents/english/icwedece.html

Organisation for Economic Co-operation and Development (OECD). 2011. Water governance in OECD countries: a multilevel approach. OECD Publishing, Paris, France.

Pahl-Wostl, C., J. Gupta, and D. Petry. 2008. Governance and the global water system: a theoretical exploration. Global Governance 14(4):419-435.

Second World Water Forum. 2000. Ministerial declaration of The Hague on water security in the 21st century. The Hague, The Netherlands. 2000. [online] URL http://www.waternunc. $\mathrm{com} / \mathrm{gb} / \mathrm{secwwf12.htm}$.

World Water Assessment Programme. 2009. The United Nations world water development report 3: water in a changing world. UNESCO, Paris, France and Earthscan, London, UK.

World Water Assessment Programme. 2012. The United Nations world water development report 4. UNESCO, Paris, France and Earthscan, London, UK. [online] URL http://www. unesco.org/new/fileadmin/MULTIMEDIA/HQ/SC/pdf/WWDR4\% 20Volume \%201-Managing $\% 20$ Water\%20under\%20Uncertainty $\%$ 20and\%20Risk.pdf . 